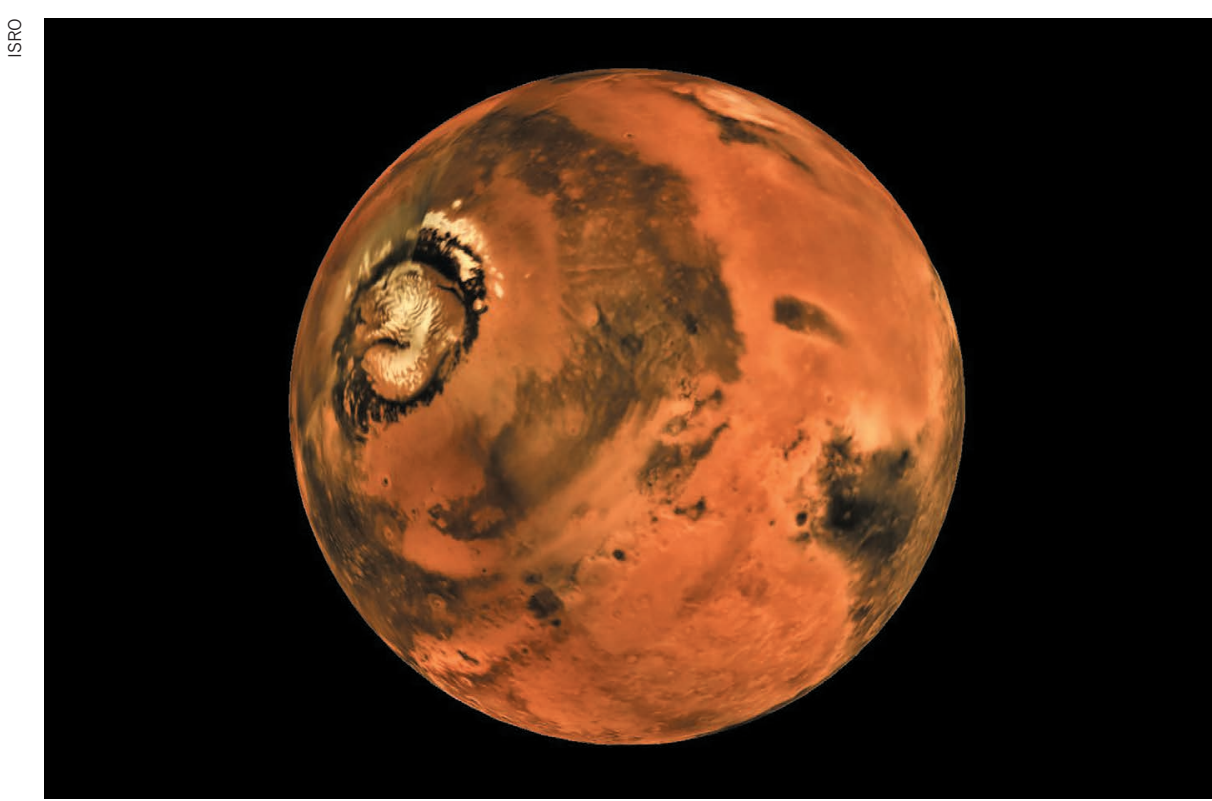

An image of Mars captured by the Indian Space Research Organisation's Mangalyaan satellite.

HISTORY

\title{
Five millennia of Indian science
}

\section{James Poskett applauds a show celebrating discovery on the subcontinent, from zero to the boson.}

\section{I} f reason can be embodied, it stares us in the face at the entrance to the Illuminating India exhibition at London's Science Museum. A 1,000-year-old statue of the Buddha sits in the 'earth witness' pose (crosslegged, right hand touching the ground), symbolizing truth and rationality. A commitment to these concepts is woven through India's 5,000-year story of science, spanning religions and philosophies from Hinduism to Sikhism, and taking in mathematics, medieval astronomy, modern physics, the computer revolution and space exploration.

The star of the show is undoubtedly part of the Bakhshali manuscript, discovered in 1881 in what is now Pakistan. This is a piece of birch bark no bigger than my hand. But the Sanskrit text on it (last month carbon dated to AD 200-400) reveals one of the most important innovations in the history of mathematics: the first use of zero as a numeral.

For much of history, there was no straightforward way to represent the concept of nothing in maths. The ancient Greeks, such as the mathematician Ptolemy, weren't even sure if zero was a number. And the lack of zero in Roman numerals often made their arithmetic needlessly complex (try adding MDCCCLVIII to MCMXLVII). The number system we use today is ultimately derived from the ancient Hindu and Arabic mathematics found in the Bakhshali manuscript.

Other incredible objects abound. I find a spectroscope built by the Nobel-prizewinning physicist Chandrasekhara Venkata Raman. A sixteenth-century Mughal painting of the Emperor Akbar riding an elephant across the Ganges is effectively a work of early natural history. A prosthetic foot developed in the 1960s by craftsman Ram Chander Sharma and orthopaedic surgeon Pramod Karan Sethi points to India's impact on the world of medicine. This is the first time many of these items have been exhibited outside India.

Vibrant textile hangings divide the show into three themes. The first, 'Observation', spans six centuries, rich with intriguing

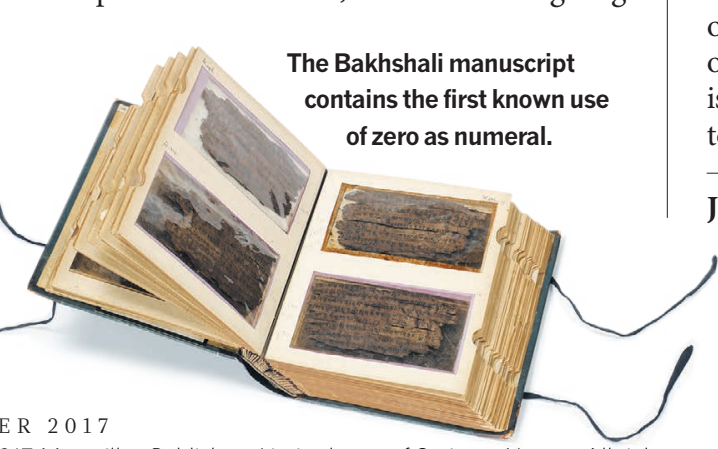

Illuminating India: 5000 Years of Science and Innovation London.

Until 31 March 2018.
The Science Museum,

juxtapositions. One moment I'm looking at a beautiful nineteenth-century astrological almanac. The next, I see a model of the camera sent to Mars in 2013 by the Indian Space Research Organisation. Part of the Mangalyaan satellite, it took detailed colour photographs of the red planet's largest canyon system, the Valles Marineris. (Incredibly, the whole mission cost under US\$75 million, less than the budget for the 2013 science-fiction blockbuster Gravity.)

Then there is a bright orange auto-rickshaw (a hybrid of an electric scooter and cycle rickshaw), the centrepiece of the 'Innovation' gallery and a symbol of India's frugal innovation, or jugaad. Alongside other classic examples of Indian engineering - such as the country's railways, which carry more than 22 million passengers each day - there is a case on telecommunications. A small wooden and metal instrument looks like the sort of thing used to tap out Morse code, but is an early example of a coherer, a device for detecting radio signals. The technology was developed by Bengali polymath Jagadish Chandra Bose, who found time to study plant physiology and archaeology in between writing science fiction and pioneering the use of semiconductors in radios. Other Indian innovations on display include the USB connector, developed by a team led by Ajay Bhatt, and the Intel Pentium processor, developed by electrical engineer Vinod Dham.

The exhibition concludes with 'Calculation'. India has produced many great mathematicians. Works by some of the best are on display: the original notebooks of the mathematical genius Srinivasa Ramanujan (A. Robinson Nature 531, 576-577; 2016) appear alongside photographs of the incredible Jantar Mantar observatory, built in Jaipur in the early eighteenth century. From here, the Maharajah Jai Singh II produced detailed astronomical calculations, comparing his results to the latest findings from Paris.

A collection of letters reminds us that the boson has its origin in India. In the 1920s, the young Bengali physicist Satyendra Nath Bose struck up a correspondence with Albert Einstein. Together, the duo laid the foundations of quantum statistics and predicted the existence of undiscovered fundamental particles. Today, we call those particles bosons in honour of S. N. Bose. Coinciding with 70 years of Indian independence, Illuminating India is a celebration of South Asian contributions to science and technology.

James Poskett is assistant professor in the history of science and technology at the University of Warwick in Coventry, UK.

e-mail:j.poskett@warwick.ac.uk 